\title{
Erratum to: De-oiled neem cake as potential bio-additive for low-salt raw skin preservation: a process for salinity reduction in tanneries
}

\author{
N. Vedaraman ${ }^{1} \cdot$ K. V. Sandhya ${ }^{1} \cdot$ V. Brindha ${ }^{2} \cdot$ A. Tamil Selvi ${ }^{2}$ - K. C. Velappan ${ }^{1}$.

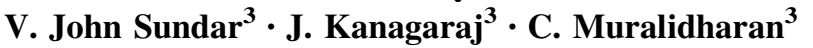

Published online: 14 June 2016

(C) Islamic Azad University (IAU) 2016

Erratum to: Int. J. Environ. Sci. Technol. (2016) 13:1563-1572

DOI 10.1007/s13762-016-0994-3

In the original publication of the article unfortunately a part of Table 11 (in the Appendix) was omitted. The correct and complete version of Table 11 is given on the next page.

The online version of the original article can be found under doi:10.1007/s13762-016-0994-3.

N. Vedaraman

vedaraman.clri@gmail.com

1 Chemical Engineering Division, CSIR-CLRI,

Adyar, Chennai 600 020, India

2 CHORD Division, CSIR-CLRI, Adyar, Chennai 600 020,

India

3 Tannery Division, CSIR-CLRI, Adyar, Chennai 600 020,

India 
Table 11 Process description for processing cured goat skins into leather

\begin{tabular}{|c|c|c|c|c|}
\hline Process & Quantity & Product & Duration & Remarks \\
\hline $\begin{array}{l}\text { Soaking I (skin weight } \\
\quad 333 \mathrm{~g} \text { ) }\end{array}$ & $\begin{array}{l}300 \%(1 \mathrm{l}) \\
0.5 \%(5 \mathrm{~g} / \mathrm{l})\end{array}$ & $\begin{array}{l}\text { Water } \\
\text { Wetting agent }\end{array}$ & $30 \mathrm{~min}$ & $\begin{array}{l}\text { Float was drained and aliquot } \\
\text { was tested for TDS }\end{array}$ \\
\hline Soaking II & $\begin{array}{l}300 \%\left(\begin{array}{ll}1 & 1) \\
0.1(1 \mathrm{~g} / \mathrm{l}) \\
0.5 \%(5 \mathrm{~g} / \mathrm{l})\end{array}\right.\end{array}$ & $\begin{array}{l}\text { Water } \\
\text { Preservative } \\
\text { Wetting agent }\end{array}$ & Left overnight & $\begin{array}{l}\text { Float was drained and aliquot } \\
\text { was tested for TDS }\end{array}$ \\
\hline Next day washing & $200 \%(650 \mathrm{ml})$ & Water & & \\
\hline Liming (skin weight $320 \mathrm{~g}$ ) & $\begin{array}{l}25 \%(80 \mathrm{ml}) \\
10 \%(400 \mathrm{~g} / \mathrm{l}) \\
3 \%(120 \mathrm{~g} / \mathrm{l}) \\
0.5 \%(20 \mathrm{~g} / \mathrm{l})\end{array}$ & $\begin{array}{l}\text { Water } \\
\text { Lime } \\
\text { Sodium sulphide } \\
\text { Wetting agent }\end{array}$ & Left overnight & $\begin{array}{l}\text { Paint prepared and applied on } \\
\text { flesh side }\end{array}$ \\
\hline Unhairing & & & & $\begin{array}{l}\text { Next day the hair was removed } \\
\text { over beam }\end{array}$ \\
\hline $\begin{array}{l}\text { Reliming (skin weight } \\
250 \mathrm{~g} \text { ) }\end{array}$ & $\begin{array}{l}200 \%(500 \mathrm{ml}) \\
5 \%(25 \mathrm{~g} / \mathrm{l})\end{array}$ & $\begin{array}{l}\text { Water } \\
\text { Lime }\end{array}$ & Left for 2 days & \\
\hline Fleshing & & & & $\begin{array}{l}\text { The limed pelts were fleshed } \\
\text { and taken for washing }\end{array}$ \\
\hline Washing & $200 \%(500 \mathrm{ml})$ & Water & $10 \min$ & \\
\hline $\begin{array}{l}\text { Deliming (skin weight } \\
200 \mathrm{~g} \text { ) }\end{array}$ & $\begin{array}{l}150 \%(300 \mathrm{ml}) \\
1 \%(6.66 \mathrm{~g} / \mathrm{l}) \\
1 \%(6.66 \mathrm{~g} / \mathrm{l})\end{array}$ & $\begin{array}{l}\text { Water } \\
\text { Ammonium chloride } \\
\text { Bating agent }\end{array}$ & Run for $1 \mathrm{~h}$ & Washed and drained $\mathrm{pH} 8-8.5$ \\
\hline Washing & $100 \%(150 \mathrm{ml})$ & Water & $10 \min$ & \\
\hline Pickling (skin weight $150 \mathrm{~g}$ ) & $\begin{array}{l}80 \%(120 \mathrm{ml}) \\
8 \%(100 \mathrm{~g} / \mathrm{l}) \\
1 \%(12.5 \mathrm{~g} / \mathrm{l}) \\
0.5 \%(6.25 \mathrm{~g} / \mathrm{l})\end{array}$ & $\begin{array}{l}\text { Water } \\
\text { Sodium chloride } \\
\text { Formic acid } \\
\text { Sulphuric acid }\end{array}$ & $\begin{array}{l}\text { Run for } 15 \mathrm{~min} \\
3 \times 10 \mathrm{~min} \text {, run for } \\
10 \mathrm{~min} \\
4 \times 15 \mathrm{~min} \text {, run for } 1 \mathrm{~h}\end{array}$ & $\mathrm{pH} 2.8-3$ \\
\hline \multicolumn{5}{|c|}{ Next day the pelts drummed for $30 \mathrm{~min} \mathrm{pH}$ at cross section adjusted to $2.8-3.0$. Then $50 \%$ of pickle bath drained } \\
\hline \multirow[t]{2}{*}{ Chrome tanning } & $\begin{array}{l}8 \%(120 \mathrm{~g} / \mathrm{l}) \\
0.5 \%(5 \mathrm{~g} / \mathrm{l})\end{array}$ & $\begin{array}{l}\text { Basic chromium sulphate } \\
\text { (BCS) } \\
\text { Sodium formate }\end{array}$ & $\begin{array}{l}2 \times 30 \mathrm{~min} \\
10 \mathrm{~min}\end{array}$ & $\begin{array}{l}\text { Check for penetration in cross } \\
\text { section }\end{array}$ \\
\hline & $1 \%(10 \mathrm{~g} / \mathrm{l})$ & Sodium bicarbonate & $3 \times 20 \mathrm{~min}$, run for $1 \mathrm{~h}$ & $\begin{array}{l}\text { Check the } \mathrm{pH} \text { to be } 3.8-4 \text {. } \\
\text { Drain the bath and pile } \\
\text { overnight }\end{array}$ \\
\hline \multicolumn{5}{|c|}{ Next day sammed and shaved to $1.0 \mathrm{~mm}$. The shaved weight noted } \\
\hline Washing & $200 \%(300 \mathrm{ml})$ & Water & $10 \mathrm{~min}$ & Drain \\
\hline Neutralization & $\begin{array}{l}150 \%(225 \mathrm{ml}) \\
0.5 \%(3.33 \mathrm{~g} / \mathrm{l}) \\
0.5 \%(3.33 \mathrm{~g} / \mathrm{l})\end{array}$ & $\begin{array}{l}\text { Water } \\
\text { Sodium formate } \\
\text { Sodium bicarbonate }\end{array}$ & $\begin{array}{l}10 \min \\
3 \times 10 \min +1 \mathrm{~h}\end{array}$ & pH 5-5.5 \\
\hline Washing & $100 \%(150 \mathrm{ml})$ & Water & $10 \mathrm{~min}$ & \\
\hline Dying and fatliquoring & $\begin{array}{l}100 \%(150 \mathrm{ml}) \\
2 \%(20 \mathrm{~g} / \mathrm{l})\end{array}$ & $\begin{array}{l}\text { Water } \\
\text { Dye }\end{array}$ & & $\mathrm{pH} 3.5$ \\
\hline & $\begin{array}{l}10 \%(100 \mathrm{~g} / \mathrm{l}) \\
8 \%(80 \mathrm{~g} / \mathrm{l}) \\
1 \%(10 \mathrm{~g} / \mathrm{l})\end{array}$ & $\begin{array}{l}\text { Fatliquor } \\
\text { Syntan } \\
\text { Formic acid }\end{array}$ & $\begin{array}{l}1 \mathrm{~h} \\
45 \mathrm{~min} \\
3 \times 5 \mathrm{~min}+40 \mathrm{~min}\end{array}$ & $\begin{array}{l}\text { Drain/wash/drain/pile over } \\
\text { night/next day hooked to dry }\end{array}$ \\
\hline
\end{tabular}

